\title{
Der Tod als Herrscher in Ugarit und Israel
}

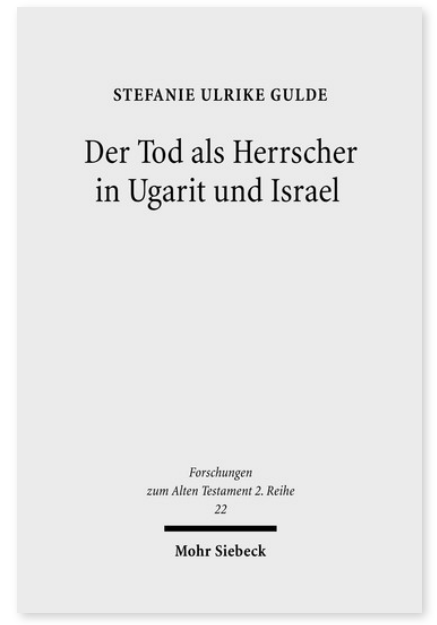

2007. XIV, 283 Seiten. FAT II 22

ISBN 978-3-16-151120-2

DOI 10.1628/978-3-16-151120-2

eBook PDF 74,00€

ISBN 978-3-16-149214-3

fadengeheftete Broschur 74,00€
Das Phänomen 'Tod' beschäftigte den Menschen zu allen Zeiten, was sich unter anderem darin zeigt, daß der Austausch über den Tod eine beträchtliche Menge an Literatur prägt. Da über den Tod an sich kein Lebender Wissen haben kann, erfolgt dieser Austausch durch alle Kulturen und Zeiten hindurch zum Großteil über bildsprachliche, besonders metaphorische Versuche. Stefanie Ulrike Gulde untersucht anhand des Phänomens 'Tod' die besonderen Möglichkeiten von Bildsprache im Alten Testament und seiner Umwelt. Gleichzeitig konzentriert sich die Autorin auf ganz bestimmte bildsprachliche Annäherungen an den Tod, die im Vorderen Alten Orient kursierten und dann auch im Alten Testament zu finden sind. Es ist der Tod als Figur, der motivgeschichtlich betrachtet wird. Diese Figur tritt in zwei unterschiedlichen Traditionen in Erscheinung, was Rückschlüsse auf den Austausch zwischen den ägyptischen, mesopotamischen und westsyrischen Kulturkreisen zuläßt. Beide Traditionen finden sich erwartungsgemäß im Alten Testament wieder. Doch sind dort auch weitere Figuren des Todes erhalten, die keine Parallelen zu Personifikationen aus der Umwelt des Alten Testaments zu haben scheinen. Sie zeugen vom souveränen Umgang der biblischen Autoren mit althergebrachten Motiven und Traditionen. Eine Gemeinsamkeit findet sich dennoch bei den verschiedenen Todesfiguren, sei es als Fresser, Eindringling oder Räuber, Hirte oder Bundespartner: Immer ist der Tod als Herrscher dargestellt. Erwartungsgemäß spiegelt dieses Attribut die Erfahrung der Machtlosigkeit der Menschen wieder, wenn es um Sterben und Tod geht.

Stefanie U. Gulde Geboren 1970; Studium der katholischen Theologie in Tübingen und Dublin; 2005 Promotion; derzeit Akademische Rätin an der Katholisch-Theologischen Fakultät in Tübingen.

\section{Jetzt bestellen:}

https://mohrsiebeck.com/buch/der-tod-als-herrscher-in-ugarit-und-israel-9783161511202?no_cache=1 order@mohrsiebeck.com

Telefon: +49 (0)7071-923-17

Telefax: +49 (0)7071-51104 